\title{
Single letter coloring and spatial cuing eliminates a semantic contribution to the Stroop effect
}

\author{
LAURIE A. MANWELL, MARTHA ANNE ROBERTS, and DEREK BESNER \\ University of Waterloo, Waterloo, Ontario, Canada
}

\begin{abstract}
Previous work has shown that the Stroop effect is reduced in size when a single letter is colored and spatially precued. The present experiment addresses a number of criticisms of this work by (1) providing a direct measure of semantic processing, (2) using a vocal response instead of a manual one, and (3) using a more appropriate baseline. A semantically based Stroop effect (slower color naming for color-associated words than for color-neutral words) is observed when all letters in the display are precued and appear in a homogeneous color. This Stroop effect is statistically eliminated when a single letter is precued and is the "odd man out" in terms of its color. Two explanations are considered. In one, single-letter coloring and cuing serve to curtail semantic processing. In the other, single-letter coloring and cuing help to keep the informational sources (i.e, color, word) separate and hence reduce interference, but semantic analysis is not curtailed. The latter account provides a more complete account of existing data.
\end{abstract}

In the Stroop paradigm, a color word distractor typically carries a color that is to be identified. Identification of the color is faster when it is congruent rather than incongruent with the color word distractor. For example, when presented with the word BLUE in the color blue, skilled readers are faster to identify the color than when the word BLUE is presented in the color yellow (Stroop, 1935; see MacLeod's [1991] review). This Stroop effect is widely interpreted as evidence that reading at the single-word level is automatic in the sense that it occurs without intent and is ballistic. That is, it is widely believed that skilled readers cannot refrain from computing the lexical and semantic representations of a word, even when this computation impairs performance (e.g., T. L. Brown, Gore, \& Carr, 2002). The present experiment is concerned with processing in the Stroop task and with the issue of whether skilled readers can refrain from computing the semantic representations of a word.

Besner and colleagues challenged the notion that various aspects of visual word recognition and semantic processing are "automatic" (e.g., Bauer \& Besner, 1997; Besner, 2001; Besner \& Stolz, 1999; Besner, Stolz, \& Boutilier, 1997; M. S. Brown, Roberts, \& Besner, 2001; Smith \& Besner, 2001; Stolz \& Besner, 1996, 1998). For example, Besner et al. (1997) reported the elimination of the Stroop effect, relative to a neutral baseline consisting of nonwords orthographically similar to color words (e.g., ret) when a

This work was supported by Grant A0998 from the Natural Sciences and Engineering Research Council of Canada to D.B. We thank Kate Stewart, Chris Blais, Nadine Laudi, Tanya Tulstonov, and Melissa Bender for assistance, and Tram Neil and two anonymous reviewers for comments. Address correspondence to D. Besner, Department of Psychology, University of Waterloo, Waterloo, ON, N2L 3G1 Canada (e-mail: dbesner@watarts.uwaterloo.ca). single letter was colored instead of the entire word. They argued, by analogy to elimination of the semantic priming effect in lexical decision when subjects search the prime for a target letter (Stolz \& Besner, 1996, 1998), that identifying the color of a single letter in the Stroop task blocks semantic activation, at least temporarily. Converging evidence comes from Besner and Stolz (1999), who reported the elimination of the Stroop effect (the difference between incongruent and neutral trials) under conditions where a single letter position is spatially precued and the letter is the "odd man out" in terms of its color as compared with the rest of the letters (where the color of the remaining letters is in the response set). The account offered for the latter result is that precuing a single letter position sets the window of spatial attention more narrowly so that word recognition processes operate much less efficiently, and that therefore lexical/semantic analyses likely do not occur.

Besner and colleagues' Stroop work has been criticized on three grounds. First, there is no direct manipulation of a semantic factor in any of the Stroop experiments. What is needed, according to Neely and Kahan (2001), is an experiment in which the interference effect produced by color-associated words (e.g., sky) is compared with a neutral baseline (the "sky/put" design). This semantic manipulation also side steps the problem that color words are normally in the response set. Second, all of Besner and colleagues' experiments employed "nonstandard" manual responses, rather than the more traditional color-naming response. This is considered inappropriate in some quarters, on the grounds that the use of such a response precludes semantic processing (e.g., Sharma \& McKenna, 1998; but see M. S. Brown \& Besner, 2001). Third, the neutral baseline in Besner et al. (1997) and Besner and Stolz (1999) consisted of ret, blat, yenile, and grend. These controls are suspect because they may phonologically prime 
color words given that they begin with the same letters as the color words in the response set (red, blue, yellow, and green). The true size of "the" Stroop effect may thus be underestimated. Indeed, when other controls are used, a residual Stroop effect is evident, so that it is ambiguous whether semantic activation has taken place or not (T. L. Brown, Joneleit, Robinson, \& C. R. Brown, 2002).

All of these criticisms are addressed here using the Besner and Stolz (1999) "odd man out" spatial cuing and coloring paradigm. More specifically, on half of the trials, all letters in a string are spatially precued and appear in a homogeneous color. On the remaining half of the trials, a single letter is precued and is colored differently from the other letters in the string (i.e., is the "odd man out" in terms of its color). This use of multicolor trials encourages participants to pay attention to the cue on single-letter colored trials. Although participants use the cue (in singleletter colored/cued procedures) at least some of the time, they may abandon reliance on the cue upon recognizing that nothing in the display requires them to use it (see Besner \& Stolz [1999] for discussion on this point). Coloring the remaining letters with a color in the response set makes attending to those elements of the display detrimental. Thus, participants are more likely to pay attention to the cue in the multicolor display (odd man out trials).

The first criticism (the failure to manipulate a semantic factor) is addressed in that a semantically based Stroop effect is measured. The second criticism (use of nonstandard responses) is addressed by using a vocal instead of a manual response. The third criticism (a neutral baseline consisting of ret, yenile, blat, and grend) is addressed by using a baseline of neutral words that have no phonological overlap with items in the response set (e.g., keg).

To preview the results, a semantically based Stroop effect is observed when all the letters in the string are cued and colored, but this Stroop effect is (statistically) eliminated when only a single letter is cued and colored. We consider two accounts of these data. In one, semantic processing of a word is blocked. In the other, single-letter coloring and cuing manipulations do not block semantic processing but instead help to hold separate the products of processing color and word dimensions. This, in turn, reduces interference.

\section{Method}

Subjects. Sixteen undergraduate students from the University of Waterloo participated in the experiment. Each subject was tested individually and paid for participating. All subjects had normal or corrected-to-normal vision and were native English speakers.

Stimuli. The stimuli consisted of the neutral words keg, jail, table, and palace; the color-associated words sky, frog, lemon, and tomato; and the color words red, blue, green, and yellow. All items were matched for length and frequency. The stimuli were presented individually, in lowercase, with one blank character space between letters (on average, a word subtended $0.9^{\circ}$ high $\times 3.1^{\circ}$ wide), and were colored using the four colors from the response set (red [RGB: 42,0,0], yellow [RGB: 63,63,21], blue [RGB: 0,42,0], and green [RGB: $0,42,0]$ ). Either all letters appeared in the same color (the allletters cued/colored condition), or one letter was colored differently from the rest (the single-letter cued/colored condition), so that all re- maining letters appeared in an incongruent color from the response set (e.g., if the target letter $k$ in $s k y$ appeared in red, then the remainder of the letters were colored yellow). Color-associated and color words were always presented in incongruent colors (i.e., sky appeared only in red, yellow, or green).

Design. The experiment consisted of a 2 cued/colored (all letters vs. single letter) $\times 3$ stimulus type (neutral vs. color-associated incongruent vs. color-word incongruent) within-subjects design. There were 48 trials at each level of cued/colored and stimulus type for a total of 288 experimental trials. All conditions varied randomly throughout the experiment in a single block of trials.

Apparatus and Procedure. Stimuli were displayed on a 17-in. Viewsonic color monitor. Stimulus presentation and data recording were controlled by Micro Experimental Laboratory 2 (MEL 2) software (Schneider, 1988), which was run on a 486 Vault PC. Subject responses were collected via a Plantronics microphone headset attached to a voice key assembly. Response times were measured to the nearest millisecond.

The subjects were seated approximately $50 \mathrm{~cm}$ from the monitor and were instructed to name the color of the letter(s) in the position(s) indicated by the white arrows. They were instructed to respond as quickly and accurately as possible and to ignore everything else in the display. The experiment began with a set of 24 practice trials that were followed by 288 experimental trials. At the beginning of each trial, a fixation cross appeared in the center of the screen. All stimuli were presented with the center letter positioned at fixation.

When ready for a trial to begin (i.e., when the subject felt that his/her gaze was focused on the fixation cross) the subject pressed the " $z$ " key on the keyboard. The fixation cross then disappeared and the screen remained blank for $400 \mathrm{msec}$, at which time a spatial cue consisting of a small arrow $\left(1.2^{\circ}\right.$ tall $)$ appeared $0.6^{\circ}$ above and below the position that would be occupied by the target letter(s). In the all-letters cued/colored condition, an arrow appeared above and below each letter position. In the single-letter cued/colored condition, an arrow appeared above and below the target letter position. The subject's task was to identify the color of the letter(s) indicated by the arrows.

The arrows appeared on the monitor for $125 \mathrm{msec}$, at which time the target string appeared. The entire display remained on the monitor until a response was made. The monitor then went blank until the experimenter coded the response as correct, incorrect, or spoiled (e.g., cough or stutter). The fixation cross then reappeared to mark the beginning of a new trial $500 \mathrm{msec}$ after the experimenter had coded the response.

\section{Results}

Incorrect responses were first removed from all reaction time (RT) analyses. Correct RTs were then subjected to a recursive data trimming procedure in which the criterion cutoff for outlier removal was established by the sample size in each condition for each subject (Van Selst \& Jolicœur, 1994). Outlier removal resulted in $2.6 \%$ of the data being discarded. RTs for correct responses and percentage error in each condition are displayed in Table 1.

Mean RTs and percentage errors were first analyzed in a $2 \times 3$ repeated measures analysis of variance (ANOVA) with cued/colored (all letters vs. single letter) and stimulus type (neutral vs. color-associated incongruent vs. colorword incongruent) as factors. This RT analysis yielded a main effect of cued/colored $\left[F(1,15)=4.50, M S_{\mathrm{e}}=\right.$ $1,172.85, p=.05]$ such that responses were faster for the all-letters cued/colored condition than for the single-letter cued/colored condition. There was a main effect of stim- 
Table 1

Mean Reaction Time (in Milliseconds) and Percent Error as a Function of Cuing/Coloring and Stimulus Type

\begin{tabular}{lccccc}
\hline & \multicolumn{2}{c}{$\begin{array}{c}\text { All Letters } \\
\text { Cued/Colored }\end{array}$} & & \multicolumn{2}{c}{$\begin{array}{c}\text { One Letter } \\
\text { Cued/Colored }\end{array}$} \\
\cline { 2 - 3 } \cline { 6 - 7 } \multicolumn{1}{c}{ Stimulus Type } & RT & \% Error & & RT & \% Error \\
\hline Incongruent & 804 & 3.6 & & 760 & 0.2 \\
Color-associated & 683 & 0.4 & & 718 & 0.5 \\
Neutral & 655 & 0.4 & & 711 & 0.3 \\
Difference & & & & & \\
$\quad$ Incongruent - Neutral & 149 & 3.2 & & 49 & -0.1 \\
$\quad$ Color-Associated - Neutral & 28 & 0.0 & & 7 & 0.2 \\
\hline
\end{tabular}

ulus type $\left[F(1,15)=30.72, M S_{\mathrm{e}}=712.76, p<.001\right]$ and, critically, an interaction between cued/colored and stimulus type $\left[F(1,15)=12.74, M S_{\mathrm{e}}=351.94, p<.005\right]$.

Analysis of the errors yielded a main effect of cued/colored $\left[F(1,15)=6.20, M S_{\mathrm{e}}=5.27, p=.05\right]$ such that more errors were made in the all-letters cued/colored condition than in the single-letter cued/colored condition. There was a main effect of stimulus type $\left[F(1,15)=5.21, M S_{\mathrm{e}}=\right.$ $7.50, p<.05]$, and an interaction between cued/ colored and stimulus type $\left[F(1,15)=6.56, M S_{\mathrm{e}}=3.05, p<.05\right]$.

Stroop interference: Color-word incongruent versus neutral stimuli. The data were then analyzed in a $2 \times 2$ repeated measures ANOVA with cued/colored (all letters vs. single letter) and stimulus type (neutral vs. color-word incongruent) as factors. The RT analysis yielded no main effect of cued/colored level $(F<1)$. There was a main effect of stimulus type $[F(1,15)=51.63$, $\left.M S_{\mathrm{e}}=3,019.92, p<.001\right]$ such that responses were slower in the color-word incongruent condition than in the neutral condition. More critically, there was an interaction between cued/colored and stimulus type in which coloring only a single letter reduced the size of the Stroop effect from 149 to $49 \mathrm{msec}\left[F(1,15)=38.88, M S_{\mathrm{e}}=\right.$ $1,023.78, p<.001]$. Planned comparisons confirmed that the 149-msec Stroop effect in the all-letters cued/colored condition was significant $[t(15)=7.12, S E M=20.88$, $p<.001]$. The residual 49-msec Stroop effect in the singleletter cued/colored condition was also significant $[t(15)=$ 5.86, $S E M=8.33, p<.001]$.

Analysis of the errors yielded a main effect of cued/colored $\left[F(1,15)=5.77, M S_{\mathrm{e}}=5.73, p<.05\right]$ such that more errors were made in the all-letters cued/colored condition than in the single-letter cued/colored condition. There was a main effect of stimulus type $\left[F(1,15)=9.12, M S_{\mathrm{e}}=\right.$ $6.59, p=.01]$ such that more errors were made in the color word incongruent condition than in the neutral condition. There was also an interaction between cued/colored and stimulus type in which coloring only a single letter reduced the size of the Stroop effect in the error data $\left[F(1,15)=7.65, M S_{\mathrm{e}}=3.27, p<.02\right]$. Planned comparisons confirmed a Stroop effect in the error data for the all-letters cued/colored condition $[t(15)=3.12$, SEM $=$ $1.02, p<.01]$, but no Stroop effect in the single-letter cued/colored condition $(t<1)$.
Semantic Stroop interference: Color-associated incongruent versus neutral stimuli. The data were also analyzed in a $2 \times 2$ repeated measures ANOVA with cued/ colored (all letters vs. single letter) and stimulus type (neutral vs. color associated incongruent) as factors. The RT analysis yielded a main effect of cued/colored $[F(1,15)=$ $\left.111.00, M S_{\mathrm{e}}=286.75, p<.001\right]$ such that responses were faster in the all-letters cued/colored condition than in the single-letter cued/colored condition. There was a main effect of stimulus type $\left[F(1,15)=9.55, M S_{\mathrm{e}}=502.65, p=\right.$ $.01]$ such that responses were slower in the color-associated incongruent condition than in the neutral condition. Most critically, there was an interaction between cued/colored and stimulus type in which coloring only a single letter reduced the size of the Stroop effect $\left[F(1,15)=7.62, M S_{\mathrm{e}}=\right.$ 228.86, $p<.02]$. Analysis of the errors yielded no main effects and no interaction (all $F_{\mathrm{s}}<1$ ).

A planned comparison confirmed that the $28-\mathrm{msec} s e-$ mantic Stroop effect in the all-letters cued/colored condition was significant $[t(15)=3.52, S E M=7.89, p<.005]$. Another planned comparison showed that the 7-msec effect in the single-letter cued/colored condition was not significant $[t(15)=1.24, S E M=5.39, p>.2]$. The power to detect a 7-msec effect was greater than .97, twotailed (using Cohen's [1988] method). This eye-catching power arose because the correlation between these two conditions was .95. Power to detect a 5-msec effect was .87 , but only .51 to detect a $3-\mathrm{msec}$ effect. Furthermore, close inspection of the data shows that a single subject with an unusually large difference score in this condition (2.7 times larger than the next largest) was inflating the size of the effect. When this subject was removed, the semantically based Stroop effect dropped to $3 \mathrm{msec}$. The other effects varied by a maximum of $4 \mathrm{msec}$. Notwithstanding Joordens and Besner (1992), who reported a significant 3-msec semantic priming effect, we are of the view that when a theory stands or falls on a 3-msec effect, it is time to pursue other questions.

\section{Discussion}

The data from this experiment can be summarized as follows. First, there was a 149-msec Stroop effect (the difference between the incongruent-color word and neutral conditions) when all-letters were cued/colored. This difference shrank to $49-\mathrm{msec}$ when a single letter was cued/ colored. The present experiment thus replicates previous findings of a reduction in the size of the Stroop effect (measured as the difference between color-word incongruent and neutral trials), when only a single letter was cued/colored as compared with when all letters were cued/ colored (e.g., Besner \& Stolz, 1999; Besner et al., 1997) though it should be noted that the manipulations used here are combinations of ones used in previous work.

The new result is that there was a 28 -msec semantically based Stroop effect (the difference between color-associated incongruent and neutral conditions) when all letters were cued/colored that was statistically eliminated when only a 
single letter was cued/colored. We now consider two accounts of this result.

Account 1: Semantic level processing is blocked. Previous work has repeatedly shown that, in the context of the semantic priming paradigm, semantic priming is eliminated when subjects search a prime for the presence of a target letter (e.g., Smith, Theodor, \& Franklin, 1983). One account of this result is that letter search on the prime blocks semantic level activation, but not lexical level activation (Stolz \& Besner, 1998). Besner et al. (1997) argued that the elimination/reduction of the Stroop effect when a single letter was colored was just another example of how semantic level processing can be blocked. It is important to note, however, that Besner et al. (1997) made an argument by analogy, given that Besner and colleagues did not employ a semantic manipulation in any of their previous Stroop experiments. Thus, the present experiment is one of only two Stroop experiments of which we are aware in which (1) semantic processing was directly manipulated and (2) this factor was crossed with the single-letter coloring and cuing manipulations. Therefore, one account is that this result is consistent with Besner et al.'s (1997) and Besner and Stolz's (1999) argument that semantic level processing is virtually completely blocked by coloring and cuing a single letter.

However, this conclusion is tempered by the results of another experiment from our lab, identical to the one reported here, with the exception that in the one-letter cued/ colored condition, the uncued letters appeared in gray (a color not in the response set). Response times were approximately $100 \mathrm{msec}$ shorter overall than in the present experiment. Furthermore, this experiment yielded an 18msec semantically based Stroop effect $[t(15)=3.41$, $S E M=5.24, p<.005]$ in the single-letter cued/colored condition. This result is problematic for Account 1, because semantic level processing is reduced but not eliminated when a single letter is cued/colored. The elimination of the semantically based Stroop effect in the present experiment may therefore reflect dilution of the Stroop effect in the single-letter cued/colored condition due to an additional source of interference produced by the presence of an irrelevant color that is part of the response set.

Account 2: Semantic level processing is not blocked. There are, however, other data that, taken together, are more difficult to reconcile with the account that singleletter coloring ever prevents semantic activation. First, MacNevin and Besner (2002) set out to directly test Besner et al.'s (1997) argument by analogy. They carried out a semantic priming experiment in which subjects identified the color of a single letter in the prime before making a lexical decision to the target. A large semantic priming effect $(66 \mathrm{msec})$ was observed, instead of finding that coloring a single letter in the prime eliminated the semantic priming effect. MacNevin and Besner discussed a number of ways in which it might be possible to reconcile this finding with (temporary) blocking of semantic activation. The fact remains, however, that coloring a single letter in the prime and having subjects identify it before making a lexical decision to a following target has a qualitatively different effect from that of carrying out a letter search on a prime before making a lexical decision to a target. In other words, Besner et al.'s (1997) appeal to the elimination of the semantic priming effect consequent to letter search on the prime is problematic as a viable analogy for why single-letter coloring reduces the size of the Stroop effect.

Second, Besner (2001) reported that it was possible to eliminate the Stroop effect under experimental conditions where only single-letter cued/colored trials were presented. Here, the Stroop effect was measured as the difference between incongruent and congruent trials, and the congruent:incongruent trial ratio was 20:80. However, negative priming was still observed. In the Stroop paradigm, negative priming is measured as the difference between trials where the color to be identified is a color word that has been ignored on the preceding trial (e.g., the word BLUE in red ink is preceded by the word RED in green ink) and trials where that is not the case (e.g., the word BLUE in red ink is preceded by the word GREEN in yellow ink). The presence of negative priming implies that the irrelevant word was processed at some point. Indeed, Besner discussed the possibility that the processing of the irrelevant word that led to the negative priming occurred off line (i.e., after the target on trial $N-1$ was responded to). Nevertheless, the main point here is that we cannot rule out the possibility that the word received lexical-semantic processing on line, but did not influence on-line performance (relatedly, see Long \& Prat, 2002).

In reaction to these findings, Besner, Wagar, and Dixon (2002) advanced the hypothesis that the reduction in the size of the Stroop effect that is driven by coloring a single element does not represent a reduction or elimination of lexical-semantic processing. Instead, they suggested that coloring a single element may simply help to keep the products of processing the different dimensions separate, and in so doing, reduce the size of the Stroop effect (see Allport, 1989). By analogy, it is well known that the Stroop effect is larger when color and word are integral rather than spatially separated (MacLeod, 1998). Besner et al. (2002) went on to demonstrate a reduction in the Stroop effect when a single element was colored in a variant of Stroop's paradigm: Subjects learned to associate shapes composed of geons with a color label. The size of the Stroop effect was reduced when a single geon was (incongruently or congruently) colored, as compared with when the entire shape was colored. Correctly identifying the shape required that subjects attend to the whole object, yet coloring a single geon still reduced the size of the Stroop effect. Thus, the effect of coloring a single element in the standard Stroop preparation does not force an account in which there is a reduction in lexical-semantic processing. ${ }^{1}$

By way of summary, a major problem that subjects face in many experiments involves discriminating relevant activation from irrelevant activation and trying to prevent crosstalk between these sources. All of the data discussed 
above, along with the present data, are consistent with the claim that coloring and cuing a single element provides subjects with a cue that helps them select a source of activation to respond to. This makes it easier to discriminate between relevant and irrelevant sources of activation, and hence reduces interference.

\section{Conclusion}

The results of the present experiment provide evidence that semantic processing of the irrelevant word can be prevented from influencing performance in the context of the Stroop paradigm. At present, this effect appears to be explained best in terms of an account in which the cuing/coloring manipulation aids subjects in distinguishing and holding separate relevant and irrelevant sources of activation, which in turn reduces interference.

\section{REFERENCES}

Allport, D. A. (1989). Visual attention. In M. I. Posner (Ed.), Foundations of cognitive science (pp. 631-682). Cambridge, MA: MIT Press.

Bauer, B., \& Besner, D. (1997). Processing in the Stroop task: Mental set as a determinant of performance. Canadian Journal of Experimental Psychology, 51, 51-68.

BESNER, D. (2001). The myth of ballistic processing: Evidence from Stroop's paradigm. Psychonomic Bulletin \& Review, 8, 324-330.

Besner, D., \& Stolz, J. A. (1999). What kind of attention modulates the Stroop effect? Psychonomic Bulletin \& Review, 6, 99-104.

Besner, D., Stolz, J. A., \& Boutilier, C. (1997). The Stroop effect and the myth of automaticity. Psychonomic Bulletin \& Review, $\underline{4}, 221-$ 225.

Besner, D., Wagar, B., \& Dixon, M. J. (2002). Reducing the size of the Stroop effect without curtailing lexical-semantic processing: Evidence from single element colouring. Manuscript submitted for publication.

Brown, M. [S.], \& BeSNer, D. (2001). On a variant of Stroop's paradigm: Which cognitions press your buttons? Memory \& Cognition, 29, 903-904.

Brown, M. S., Roberts, M. A., \& Besner, D. (2001). Semantic processing in visual word recognition: Activation blocking and domain specificity. Psychonomic Bulletin \& Review, 8, 778-784.

Brown, T. L., GoRE, C. L., \& CARR, T. H. (2002). Visual attention and word recognition in Stroop color-naming: Is word recognition "automatic"? Journal of Experimental Psychology: General, 131, 220-240.

Brown, T. L., Joneleit, K., Robinson, C. S., \& Brown, C. R. (2002). Automaticity in reading and the Stroop task: Testing the limits of involuntary word processing. American Journal of Psychology, 115, 515-543.

COHEN, J. (1988). Statistical power analyses for the behavioral sciences. (2nd ed.). Hillsdale, NJ: Erlbaum.

JoORDENS, S., \& BESNER, D. (1992). Priming across an intervening unrelated word: Implications for models of memory and retrieval. Journal of Experimental Psychology: Learning, Memory, \& Cognition, 18, 483-491.

LoNG, D. L., \& Prat, C. S. (2002). Working memory and Stroop interference: An individual differences investigation. Memory \& Cognition, 30, 294-301.
MacLeod, C. M. (1991). Half a century of research on the Stroop effect: An integrative review. Psychological Bulletin, 109, 163-203.

MacLeOD, C. M. (1998). Training on integrated versus separated Stroop tasks: The progression of interference and facilitation. Memory \& Cognition, 26, 201-211.

MACNEVIN, C., \& BESNER, D. (2002). When are morphemic and semantic priming observed in visual word recognition? Canadian Journal of Experimental Psychology, 56, 112-119.

NeELY, J. H., \& KaHAN, T. (2001). Is semantic activation automatic? A critical re-evaluation. In H. L. Roediger III, J. S. Nairne, I. Neath, and A. M. Surprenant (Eds.), The nature of remembering: Essays in honor of Robert G. Crowder (pp. 69-93). Washington, DC: American Psychological Association.

Raz, A., Shapiro, T., Fan, J., \& Posner, M. I. (2002). Hypnotic suggestion and the modulation of the Stroop interference. Archives of General Psychiatry, 59, 1155-1161.

RisKo, E. F., STOLZ, J. A., \& BESNER, D. (in press). Basic processes in reading: Is visual word recognition obligatory? Psychonomic Bulletin \& Review.

SCHNEIDER, W. (1988). Micro Experimental Laboratory: An integrated system for IBM PC compatibles. Behavior Research Methods, Instruments, \& Computers, 206-217.

Sharma, D., \& McKenna, F. P. (1998). Differential components of the manual and vocal Stroop tasks. Memory \& Cognition, 26, 1033-1040.

SMith, M. C., \& BeSner, D. (2001). Modulating semantic feedback in visual word recognition. Psychonomic Bulletin \& Review, 8, 111-117.

SMith, M. C., Theodor, L., \& FrankLIN, P. E. (1983). The relationship between contextual facilitation and depth of processing. Journal of Experimental Psychology: Learning, Memory, \& Cognition, 9, 697712.

Stolz, J. A., \& BeSner, D. (1996). Role of set in visual word recognition: Activation and activation blocking as nonautomatic processes. Journal of Experimental Psychology: Human Perception \& Performance, 22, 1166-1177.

StOLZ, J. A., \& BESNER, D. (1998). Levels of representation in visual word recognition: A dissociation between morphological and semantic processing. Journal of Experimental Psychology: Human Perception \& Performance, 24, 1642-1655.

StOLZ, J. A., \& MCCANN, R. S. (2000). Visual word recognition: Reattending to the role of spatial attention. Journal of Experimental Psychology: Human Perception \& Performance, 26, 1320-1331.

STROOP, J. R. (1935). Studies of interference in serial verbal reactions. Journal of Experimental Psychology, 18, 643-662.

VAN SELST, M., \& JoliCEUR, P. (1994). A solution to the effect of sample size on outlier estimation. Quarterly Journal of Experimental Psychology, 47A, 631-650.

\section{NOTE}

1. That said, other manipulations produce results that do challenge the idea that semantic processing in the Stroop task, semantic priming, and other paradigms is automatic (M. S. Brown et al., 2001; Raz, Shapiro, Fan, \& Posner, 2002; Risko, Stolz, \& Besner, in press; Smith \& Besner, 2001; Stolz \& Besner, 1998; Stolz \& McCann, 2000). Thus, we hold the view that semantic processing in visual word recognition is not automatic.

(Manuscript received August 20, 2002; revision accepted for publication February 24, 2003.) 